\title{
Border Carbon Adjustments and Industrial Competitiveness in a European Green Deal
}

\author{
Stuart Evans ${ }^{1,2}$, Michael A. Mehling 3 , Robert A. Ritz ${ }^{1,4}{ }^{*}$, Paul Sammon ${ }^{5}$
}

This version: November 2020

First version: May 2020

\begin{abstract}
As part of the European Green Deal, the EU is considering the introduction of a Border Carbon Adjustment (BCA) on imports as an alternative to free allocation of emission allowances to reduce the risk of carbon leakage under the EU's Emissions Trading System (EU ETS). While a BCA for exports is not categorically excluded, it is less likely to be consistent with World Trade Organisation rules and therefore less likely to be proposed than an import-only BCA. In this paper, we show that replacing free allocation by an import-only BCA would weaken the competitiveness of EU producers in foreign markets. Free allocation also helps support the cost competitiveness of domestic products that are exported to non-EU markets. Therefore, a move to import-only BCAs does not necessarily make redundant the continued use of free allocation to help safeguard overall industrial competitiveness. While combining an import BCA with free allocation for exports can increase the risk of legal challenges, such risks may be reduced with an appropriate design. More broadly, policymakers need to navigate a complex trade-off between competitiveness support, a stronger carbon price signal, and extra fiscal revenue.
\end{abstract}

Keywords: Border carbon adjustment, carbon pricing, competitiveness, free allocation, international trade JEL codes: H23, K33, Q5

\section{Key policy insights}

- A BCA on imports levels the playing field in domestic EU markets but does not provide competitiveness support to exports

- Therefore, a move to an import-only BCAs does not obviate the need for free allocation to safeguard overall industrial competitiveness

- While combining an import-only BCA with free allocation for exports increases the risk of legal challenges, such risks may be reduced with an appropriate design 


\section{Introduction and Policy Context}

Designing a carbon pricing mechanism that drives industrial decarbonisation while also safeguarding international competitiveness presents a major dilemma for policymakers. While an increasing share of global industrial emissions is subject to carbon pricing (World Bank 2020), coverage is likely to remain uneven in the near term. As a result, carbon pricing can undermine the international competitiveness of a country's emissions-intensive and trade-exposed (EITE) sectors. Closely related, this gives rise to the risk of 'carbon leakage' - where production or investment is offshored to jurisdictions without a carbon price in order to avoid carbon costs. The economic, environmental, and political consequences of leakage risk make it one of the most contentious issues when designing a carbon pricing instrument.

The EU's Emissions Trading System (EU ETS) and other jurisdictions currently provide emissions allowances (permits) for free to EITE sectors, such as cement, chemicals and steel, that are deemed at risk of carbon leakage. Free allocation can mitigate the cost increases incurred by domestic producers due to carbon pricing, and thereby can offset the potential loss of competitiveness relative to less regulated international competitors - and thus reduce the risk of carbon leakage. Yet this approach has also faced criticism for muting the carbon price signal (Pollitt, Neuhoff \& Lin, 2020) and conflicting with the 'polluter pays' principle. Moreover, an increasing push for countries to target 'net zero' emissions - in line with the IPCC's (2018) findings on the requirements to limit global warming to $1.5^{\circ} \mathrm{C}-$ constrains their ability to continue to provide free allocation at current levels.

In the EU, there is political momentum towards a Border Carbon Adjustment (BCA) as a mechanism to support industrial decarbonisation. A significant shift occurred in July 2019 when then-incoming European Commission President Ursula von der Leyen suggested that BCAs would be central to plans for a European Green Deal. The European Commission's communication on the European Green Deal notes that "the Commission will propose a carbon border adjustment mechanism, for selected sectors, to reduce the risk of carbon leakage" and that "it would be an alternative to the measures - such as the free allocation of emissions allowances or compensation for the increase in electricity costs - that address the risk of carbon leakage in the EU's Emissions Trading System" (European Commission 2019, p. 5). ${ }^{6}$ BCAs could prove to be a key element of the EU strategy to drive greater emissions reductions domestically - while also incentivising action in laggard jurisdictions. ${ }^{7}$

To get the policy design right, it is essential that these issues are fully understood. In March 2020, the European Commission solicited feedback on the BCA roadmap, followed by a public consultation that started in July and concluded in October 2020. 
All implementation options for a BCA outlined by the European Commission would impose some form of compliance obligation - effectively a carbon 'top-up fee' - on imports at the border (European Commission 2020). ${ }^{8}$ In principle, this would be levied according to the quantity of carbon emissions associated with the imported product and the shortfall in carbon pricing coverage of those emissions (the difference between the home and foreign carbon price applicable to a given product). Such a BCA on imports could reduce leakage risk by ensuring that domestic producers do not face an asymmetric carbon price in their home market and thereby facilitate the removal of free allocation. The implementation options also have in common that they are currently being discussed for imports only, not for exports by EU producers. While a BCA for exports is not categorically excluded, it is less likely to be legally consistent with World Trade Organisation (WTO) rules (as discussed further below). ${ }^{9}$ During the public consultation period mentioned above, several industry associations and individual companies potentially covered by the BCA already expressed strong concern about the effects of a phase-out of free allocation without adequate safeguards for European exports.

This paper provides an interdisciplinary analysis that combines economic, legal and policy perspectives, with a focus on the competitiveness implications of BCA design on EITE sectors. More formally, we present a simple economic model of the degree of substitution between the two policy instruments: a BCA on imports, and free allocation. Our contribution with this paper is thus a stylized comparison of different BCA implementation options, with an emphasis on limits to competitiveness protection given by import-only BCAs.

Our paper proceeds as follows. Section 2 reviews previous literature on the topic, and Section 3 introduces a simple 'ABC framework' through which to understand the drivers of industrial competitiveness under asymmetric carbon pricing. Section 4 provides a simple economic analysis of the extent to which BCAs and free allocation are substitutes in terms of their competitiveness impacts. Section 5 discusses legal considerations relevant for, respectively, the implementation of an EU BCA on exports and the combination of an EU BCA on imports with continued free allocation for exports. Section 6 concludes.

\section{Related literature}

This paper relates to three main strands of literature: (1) on competitiveness and leakage impacts of carbon pricing, (2) on the economics of border carbon adjustments, and (3) on the international law of border carbon adjustments. First, this paper sits within the context of literature on the competitiveness impacts of carbon pricing and concerns about carbon leakage. Early work by Reinaud (2005) focused on 
understanding the magnitude of production cost increases incurred by EITE sectors in the EU ETS, in light of the extent of (grandfathered) free allocation. All else equal, a greater increase in production costs leads to a greater concern about potential for production and employment losses and for carbon leakage - whereby emissions are offshored to outside the EU. Demailly \& Quirion (2006) find that output-based allocation (OBA), that is linked to a firm's current production levels, significantly enhances the ability of free allocation to mitigate carbon leakage..$^{10}$ Over the last 15 years, numerous studies have sought to estimate (short-term) competitiveness and leakage impacts for individual sectors, notably cement and steel; Martin, Muûls \& Wagner (2016), Dechezleprêtre \& Sato (2017), Joltreau \& Sommerfeld (2019) and Venmans, Ellis \& Nachtigall (2020) provide useful reviews of this literature. ${ }^{11}$ While most empirical work has found little evidence for competitiveness and leakage impacts under the EU ETS to date (e.g., Branger, Quirion \& Chevallier, 2016; Naegele \& Zaklan, 2019), there is a risk that these may become more pronounced in future with a more ambitious EU carbon price and greater auctioning of allowances. Our contribution reflects recent EU policy developments, through the lens of a simple $\mathrm{ABC}$ framework that captures both short- and long-run competitiveness and different types of free allocation. ${ }^{12}$

Second, the design of BCAs and their rationale have been explored in a strand of the wider literature on carbon competitiveness. In a cross-model analysis, Böhringer, Balistreri \& Rutherford (2012) find that a BCA on imports can significantly reduce carbon leakage to external jurisdictions. Fischer \& Fox (2012) provide a detailed model-based economic comparison of different approaches to BCA implementation and find that a combined import- and export-BCA is usually most effective at combatting carbon leakage. Hecht \& Peters (2019) consider the impacts of BCA in a partial equilibrium model that, similar to us, uses the equalization of carbon costs between domestic and external firms as the metric by which BCAs can achieve "competition neutrality". ${ }^{13}$ Cosbey, Droege, Fischer \& Munnings (2019) provide a useful synthesis of the main findings from the BCA literature to date. More broadly, Helm, Hepburn \& Ruta (2012) argue that the adoption of an import-BCA by one region can provide dynamic incentives for stronger carbon pricing in other regions (so as to capture the additional tax revenue).

Third, legal implications of BCAs, and notably their compatibility with international trade law, have been extensively studied in the literature. Following earlier studies on the legality of border tax adjustments (BTAs) for environmental and energy taxes, Ismer \& Neuhoff (2004) offer one of the earliest analyses of border adjustments and their legality as a tool of climate policy, concluding that a BCA for imports and exports would be admissible under WTO rules provided it is calculated on the basis of a best available technology standard (Ismer \& Neuhoff, 2004). De Cendra (2006) 
analyses the legality of border adjustments for exports, and concludes that the relevant WTO rules lack clear guidance on the question. A joint report by the WTO and United Nations Environment Programme (UNEP) affirms that WTO rules permit the use of BTAs on exported products under certain conditions, but does not conclusively state whether allowances under an ETS can be considered akin to an adjustable tax. Likewise, Hillman (2013) - a former member of the WTO Appellate Body-echoes the view that export BTAs can be legal, but does not extend her analysis to free allocation under an ETS. Holzer (2014) argues that exports would only be eligible for adjustment at the border if the costs accruing under an ETS could be considered an indirect tax, something she considers unlikely. Mehling, van Asselt, Droege, Das \& Verkuijl (2019) take a more favourable view on the classification of emissions trading as an indirect tax, but caution against compensating exports at levels that exceed the carbon constraint borne by products sold domestically.

\section{ABC Competitiveness Framework}

A simple three-channel ABC framework, illustrated in Figure 1, helps to understand the competitiveness impacts on EITE sectors under carbon pricing. All three channels matter for a holistic assessment of how different policy options can safeguard EITE competitiveness and, closely related, mitigate the risk of carbon leakage.

In the short run, the competitiveness of domestic companies operating in EITE sectors can vary along two channels. Channel A reflects the competitiveness of their production in domestic markets relative to imports from rivals based in external jurisdictions. Channel B is their competitiveness in external markets to which they export. Given the limited degree of product differentiation that is common to EITE sectors, these short-run channels of competitiveness impacts are importantly driven by the short-run marginal cost of production of domestic producers relative to that of their rivals across both markets - which depend, in part, on the design of carbon prices.

Over the longer run, in addition, Channel $\mathrm{C}$ captures the competitiveness of existing productive capacity or new investment that may serve both domestic and external markets. This long-term channel will, in general, also depend on the long-run marginal cost, which includes the cost of capital. The impacts of Channels A and B on short-run profitability will be an important driver of any longer-term competitiveness along Channel $\mathrm{C}$; that is, any short-run competitive distortions along Channels A and B may also affect firms' long-term decisions about capacity and investment. Hence an immediate priority for policy, and our main focus in this paper, often lies in addressing the short-term Channels A and B. ${ }^{14}$

\section{Free allocation and competitiveness}


Free allocation of emissions allowances can, in principle, safeguard against all three channels of industrial competitiveness - but the method of free allocation has important implications for which channels are addressed. Free allocation has three main forms, each with different implications for the competitiveness:

1. Grandfathering: Grandfathered allowances that are based solely on historical emissions are equivalent to a lump-sum transfer that has no impact on the short-run marginal cost of production. ${ }^{15}$ Marginal cost rises according to the carbon price (the marginal cost of emissions), while free allocation is invariant to production levels so it provides no offsetting cost reduction. As such, 'pure' grandfathering therefore does not address Channel A or B. However, it can affect Channel $\mathrm{C}$ by forestalling closure of productive capacity, as some continued level of production is usually a requirement for assistance.

2. Output-based allocation: At the opposite end, output-based allocation (OBA) explicitly links the extent of a domestic firm's free allocation to current production levels. In this case, the short-run marginal cost of production is increased by the marginal cost of emissions but the link at the margin between free allocation and production partially (or even fully) offset the increased cost of emissions. This de facto subsidy to output therefore directly supports domestic firms' competitiveness along both Channels A and B. By previous arguments, this will also enhance the long-term Channel C.

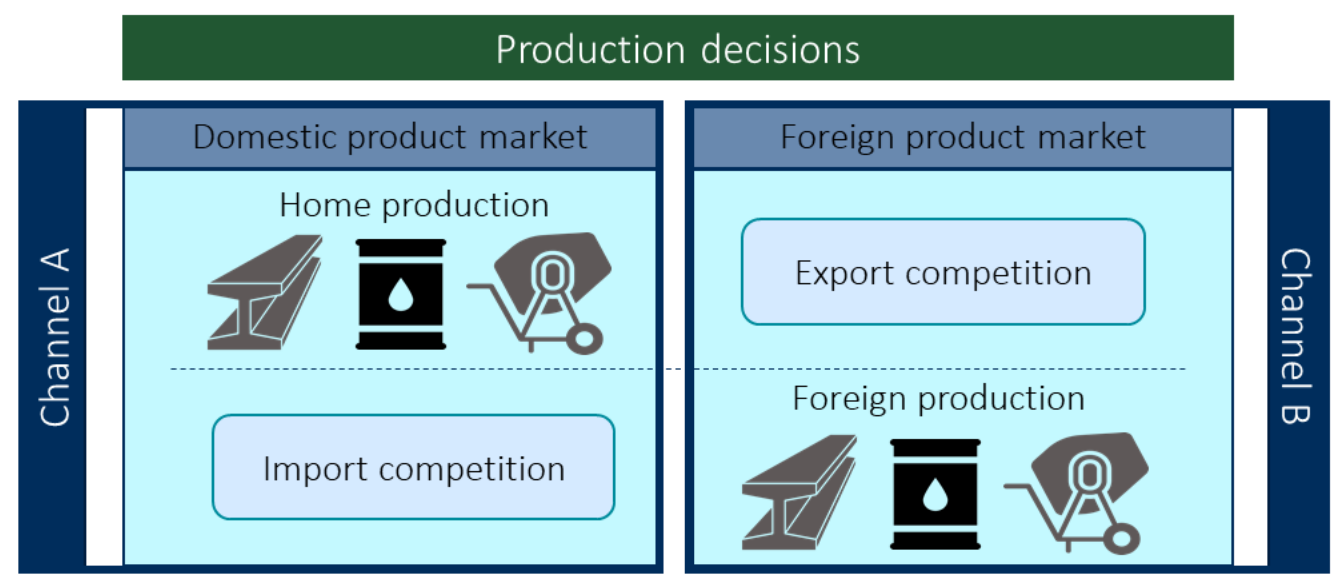

Capital decisions

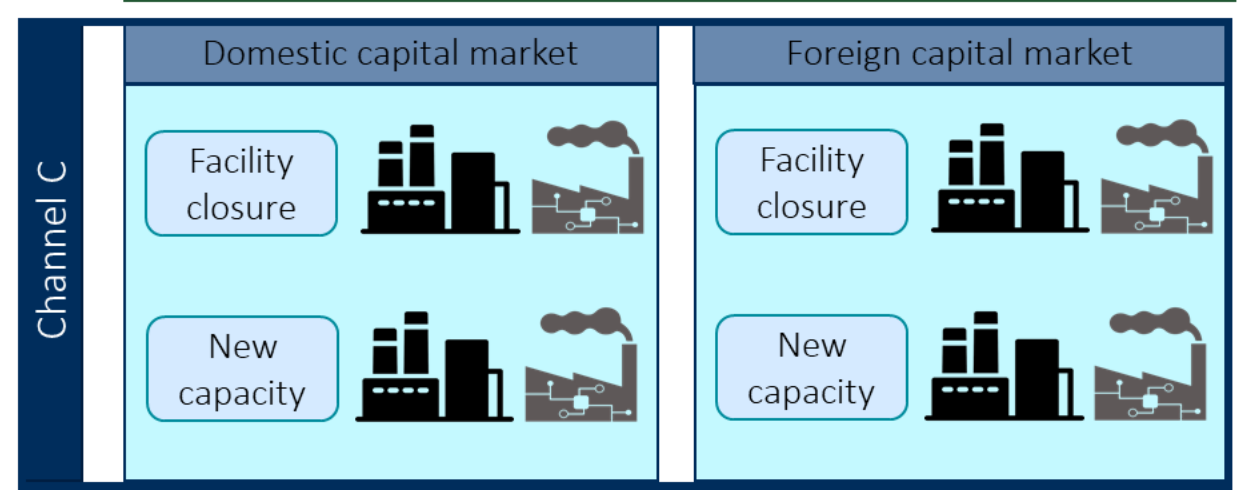


Figure 1: ABC framework of short- and long-run competitiveness channels

3. Hybrid allocation: Current EU ETS policy is a hybrid form of free allocation that combines elements of grandfathering and OBA with product specific benchmarks that limit allocations according to the best-performing companies in an EITE sector (and with a minimum production threshold for firms to receive their full free allocation entitlement). Its fixed baseline period limits the degree to which allocations adjust with production levels. As such, this approach addresses Channels A and B only up to the point the production threshold is reached, but can affect Channel $\mathrm{C}$ by supporting utilisation of existing capacity up to the threshold level. ${ }^{16}$

The central point is that common forms of free allocation, due to their link to production levels, in practice mitigate some combination of the short-run Channels $\mathrm{A}$ and $\mathrm{B}$ and long-run Channel C. ${ }^{17}$ While this helps domestic companies compete in both domestic and external markets, a muted short-run carbon price blunts the incentive for abatement in domestic EITE industries.

\section{Import-only BCA and competitiveness.}

The framework makes clear how a BCA that is levied only on imports (to avoid potential legal concerns) supports EITE competitiveness primarily along the shortrun Channel A. An import-only BCA serves as a top-up carbon fee on products sold to the domestic market by companies from external jurisdictions (with zero or at least lower carbon prices). In this way, it raises the marginal cost of export for these external companies; this, in turn, supports the competitiveness of domestic producers along Channel A of the framework. However, the BCA on imports has no effect on Channel B because it leaves unchanged the relative costs of domestic and external companies for sales to external jurisdictions. Given this remaining asymmetry in short-term competitiveness along Channel B, it is unlikely that such a BCA on imports only will have a sufficiently strong effect on the longer-term competitiveness channel C. However, this BCA does maintain the strength of the domestic carbon price signal and therefore does not blunt abatement incentives in the way that free allocation can.

\section{Economic Analysis of Border Carbon Adjustments vs. Free Allocation}

We now use a simple economic model to explain more formally the extent of substitutability between free allocation and a BCA levied on imports. For simplicity, we assume that the world is split into two regions: the European Union (EU) and the rest of the world (ROW). Carbon prices are written as $t_{i}$ and $t_{j}$, respectively, where the EU has a higher carbon price than that in effect in the ROW, with $t_{i}>t_{j}$. The ROW carbon price can be interpreted as an average across a larger number of non-EU 
countries. Our analysis takes the carbon prices $t_{i}$ and $t_{j}$ as given and fixed, rather than these also being policy instruments. For the EU ETS, this assumption can be justified by the carbon price being significantly driven by electricity generation, which is not exposed to international competition in the way that industrial sectors are.

Free allocation that is linked to production levels - such as OBA and hybrid allocation-dilutes the carbon price faced at the margin by domestic producers making short run production decisions. Thus the 'effective' carbon price lies below the market price of carbon. We capture this impact of free allocation using the parameters $f_{i}$ and $f_{j}$, both on $[0,1]$, where a value of zero means no dilution and a value of one represents full dilution of the carbon price. OBA and the current hybrid EU allowance policy corresponds to $0<f_{i}<1$ while pure grandfathering is nested where $f_{i}=0$. In sum, effective carbon prices in the EU and ROW are therefore given by $\left(1-f_{i}\right) t_{i}$ and $\left(1-f_{j}\right) t_{j}$.

We wish to compare free allocation with an import-only BCA in terms of the competitiveness support each provides. Unlike the carbon price dilution under free allocation, a BCA tops up the carbon price faced by imports; its analytics are detailed below. As a simple proxy for competitiveness concerns, we consider the EU's policy objective to be a level playing field in effective carbon prices using free allocation and/or a BCA on imports. ${ }^{18}$ (We argue further below that similar conclusions would be obtained under alternative metrics for competitiveness.) As is well-known, equalization of carbon prices also leads to an equalization of marginal abatement costs across jurisdictions, which is the basic cost-efficiency property of carbon pricing. We assume a preference for using as little free allocation as possible to achieve the policy objective. In view of the EU's current proposals, our main question is to what extent a new import-only BCA substitutes for free allocation.

Case 1: A local perspective on competitiveness. Motivated by our ABC framework, consider first a local perspective on competition focused on domestic production by EU-based producers competing with ROW imports. In the absence of a BCA, effective carbon prices for EU and ROW producers are $\left(1-f_{i}\right) t_{i}$ and $\left(1-f_{j}\right) t_{j}$. These effective carbon prices are equalized if the degree of free allocation to EU-based producers is equal to $f_{i}=\left[1-\left(1-f_{j}\right)\left(t_{j} / t_{i}\right)\right] \equiv f_{i}^{*}$. This serves as a benchmark against which to compare the effects of the introduction of a BCA. This 'optimal' degree of free allocation is always positive, $f_{i}^{*}>0$, as a direct consequence of the EU having a higher carbon price than the ROW. A lower degree of free allocation is needed if either the ROW has a higher carbon price or itself provides less free allocation.

In this case, both free allocation and a BCA can level the playing field in terms of effective carbon prices. To see why, suppose that the EU also introduces a BCA on imports. With the BCA, the effective carbon price that ROW producers face when selling into the EU becomes $\left(1-f_{j}\right) t_{j}+b_{i}\left[\left(1-f_{i}\right) t_{i}-\left(1-f_{j}\right) t_{j}\right]$, where the parameter $b_{i}$, also on 
$[0,1]$, measures the extent of the top-up implied by the BCA. By design, therefore, a 'full' BCA, with $b_{i}=1$, by construction equalizes effective carbon prices at $\left(1-f_{i}\right) t_{i}-$ regardless of the degree of free allocation. Similarly, equalization again occurs where free allocation is at the level $f_{i}=f_{i}^{*}$-regardless of the existence or extent of the BCA.

This local perspective suggests that the EU has two distinct policy options to maintain industrial competitiveness: either it can continue the use of free allocation at the level $f_{i}=f_{i}^{*}$ and not rely on a BCA at all; or it can switch to a full BCA on imports, with $b_{i}=1$, and discontinue free allocation. In other words, this local perspective suggests a strong element of policy substitution: optimal use of one policy instrument makes redundant the use of the other. This reasoning is in line with recent EU policy discussions that envision a BCA replacing free allocation for the sectors in which it applies. Indeed, a particular attraction of the import-only BCA is that, unlike free allocation, it maintains the carbon price signal for abatement - and also raises additional government revenue for EU countries.

However, there are at least two shortcomings to this local perspective. First, while it 'solves' Channel A of our ABC competitiveness framework, it ignores Channel B: EU companies will still face asymmetric carbon prices in their export markets. Second, because of this, it also leaves open the possibility that long-run returns on investment will nonetheless be lower in the EU. With EU firms still facing an uneven playing field in ROW markets, this may impact decisions regarding current capacity or investment in new capacity - Channel C. This could lead to early closure of industrial plants, forestall upgrades to improve productivity, and see investment in new capacity in ROW that may otherwise have occurred in the EU.

Case 2: A global perspective on competitiveness. Now consider a fuller picture that captures global competitiveness, that is, includes the position of EU producers that export to ROW markets as well as selling domestically. As a benchmark, with free allocation yet without a BCA, effective carbon prices are $\left(1-f_{i}\right) t_{i}$ for EU producers in both their EU and ROW markets, and $\left(1-f_{j}\right) t_{j}$ for ROW producers also in both markets. So effective carbon prices are again equalized if the EU's free allocation is equal to $f_{i}=\left[1-\left(1-f_{j}\right)\left(t_{j} / t_{i}\right)\right] \equiv f_{i}^{*}$. Crucially, this degree of free allocation restores the level playing field across both EU and ROW markets. In this sense, the previous finding on free allocation is robust to a multi-market perspective.

The introduction of a BCA on imports by the EU again has no effect on the effective carbon price of EU producers, which remains $\left(1-f_{i}\right) t_{i}$ in both their domestic and export markets. For ROW producers, the key implication is that their effective carbon price in their domestic markets also remains unaffected at $\left(1-f_{j}\right) t_{j}$ by the BCA on imports. Like before, their effective carbon price on exports to the EU becomes $\left(1-f_{j}\right) t_{j}+b_{i}\left[\left(1-f_{i}\right) t_{i-}\right.$ $\left.\left(1-f_{j}\right) t_{j}\right]$. This leads immediately to the conclusion that now a full BCA $\left(b_{i}=1\right)$ is unable to equalize effective carbon prices globally as it cannot 'reach' competitive conditions 
in ROW markets. Effective carbon prices are equalized for both producer types in both markets as long as $\left(1-f_{i}\right) t_{i}=\left(1-f_{j}\right) t_{j}+b_{i}\left[\left(1-f_{i}\right) t_{i}-\left(1-f_{j}\right) t_{j}\right]=\left(1-f_{j}\right) t_{j}$. It is easy to verify that this condition is, once again, satisfied by a free allocation $f_{i}=\left[1-\left(1-f_{j}\right)\left(t_{j} / t_{i}\right)\right] \equiv f_{i}^{*}$, regardless of the degree of $\mathrm{BCA}$. As a result, moving to a BCA here comes with zero policy substitution: the same level of free allocation remains optimal for 'global' competitiveness. This demonstrates that an import-only BCA is insufficient to fully address all competitiveness channels underlying the $\mathrm{ABC}$ framework.

A simple metric that captures the potential limitations of import-only BCAs as a competitiveness instrument is the export reliance of domestic producers. In the EU, a large proportion of products on the carbon-leakage list corresponds to major exporting industrial sectors. As an illustration, Figure 2 shows potential export exposure of the steel industry in 2017. In that year, this sector accounted for nearly $€ 128$ billion in gross value added (GVA) and supported nearly 2.5 million European workers directly and indirectly. ${ }^{19}$ Around $15 \%$ of EU finished steel products are thus exported to ROW destinations, with the US and Turkey as the top two EU export destinations. Each of these countries has a large steel production base and a relatively low likelihood of placing a price on industrial carbon emissions in the near term - given that Turkey has not yet ratified the Paris Agreement, and prospects of a federal price on carbon in the USA are fleeting, even following the 2020 federal election. Failure to account for the export dynamics of such sectors when designing a BCA could hence create a risk of carbon leakage if demand in export markets shifts to alternative higher emissions-intensity producers in jurisdictions without an equivalent carbon price. In short, even if Channel A from our framework is typically even larger, the export-driven Channel B is still an important one.

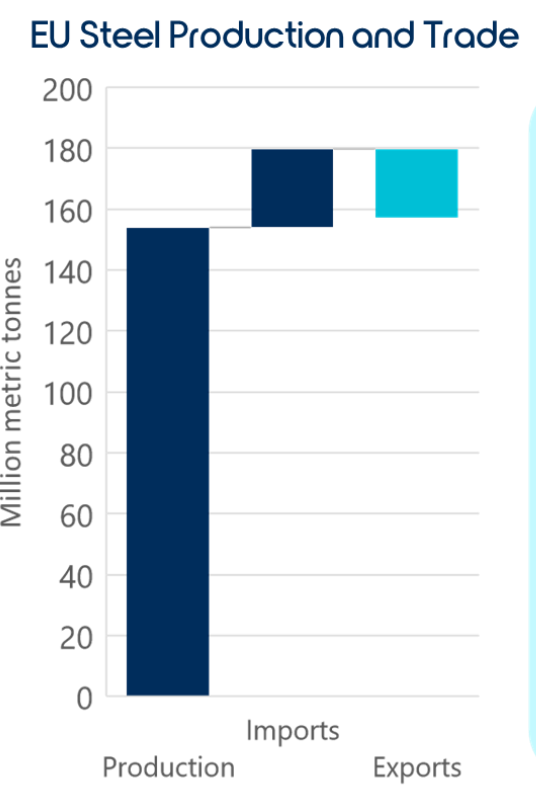

\section{Top 10 Export Destinations}

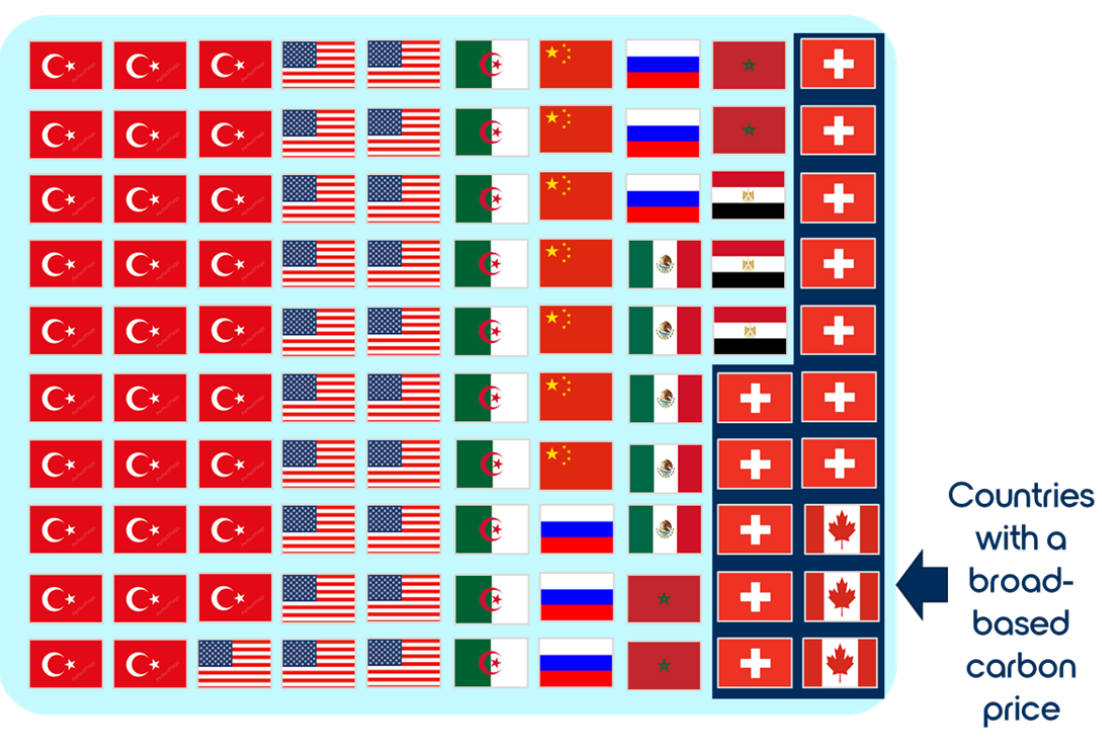

Figure 2: Illustration of EU steel exposure to export market 
Source: Based on data from Eurofer (2018), European Steel in Figures; each flag represents $1 \%$ of the top 10 destinations in 2017

The above analysis shows that free allocation and import-only BCAs have limited substitutability using one of the simplest metrics of competitiveness: equalization of effective carbon prices. Other competitiveness metrics such as EU companies' market share, profitability, and production volumes could also be considered. However, with higher relative carbon costs likely to result in lower market share, profitability, and production volumes, our basic conclusion should continue to apply: introducing an import-BCA may well allow the level of free allocation to be reduced - but not to zero. Absent some other form of export-BCA, both policy levers will be needed to fully address the full array of competitiveness concerns under the ABC framework.

Our formal analysis so far has deliberately focused narrowly on competitiveness concerns; other economic and political factors may favour a BCA over free allocation. For instance, a BCA transfers some of the EU's abatement incentive to non-EU producers - and therefore may drive additional global emissions cuts. BCAs increase government revenues, by reducing foregone auction revenue and generating additional fiscal revenue at the border. BCAs may also drive increased uptake of carbon pricing in ROW jurisdictions, particularly where the EU is an important destination market for ROW products, and these jurisdictions seek to capture carbon revenues domestically (Helm, Hepburn \& Ruta 2012). Such an adoption dynamic could, over time, level the playing-field on carbon pricing globally, and reduce the need for assistance to address the competitiveness and leakage risks.

More broadly, our analysis suggests that policymakers in the EU and elsewhere need to navigate a complex trade-off between free allocation and BCAs, and this may be different depending on each sector's economic characteristics. While free allocation can offer more holistic competitiveness support, BCAs can lead to a stronger carbon price signal for both domestic and external producers and raise additional government revenue. At the same time, the introduction of BCAs raises considerable administrative and legal challenges, while free allocation is already in place and enjoys relatively broad acceptance among ETS stakeholders within industry. These trade-offs can resolve differently across EITE sectors depending on the extent of their export reliance and on the value of a stronger abatement incentive. Our analysis highlights the need for careful consideration of internal and external market dynamics, and potential policy interactions for the EU to develop a coherent policy mix.

\section{Summary of Legal Issues}


While EU statements to date suggest that it is considering a BCA on imports only, a BCA can, in principle, also apply to exports; that is, it can adjust for climate-policy asymmetries at the border when domestic products leave the EU to be sold in external markets. Such adjustment could occur in the form of an exemption, regulatory relief, or compensation payment. For example, products destined for export markets could be exempt from the need to pay the carbon price on emissions associated with their production. In doing so, however, an export BCA incurs a twofold risk of violating international trade law:

1. Relief or compensation for exports would reduce the reach of the EU's carbon price - which currently covers emissions associated with production of exported goods. Because it reduces the degree to which carbon costs are internalized across the EU, such an export BCA is thus less likely to be considered a measure necessary to protect the environment or related to the conservation of exhaustible resources (Marcu, Mehling \& Cosbey 2020). That, in turn, would mean that an export BCA may not benefit from the exemption of Article XX of the General Agreement on Tariffs and Trade (GATT). Because a BCA only applied to exports would not apply to goods from trade partners, however, it is unlikely to be considered discriminatory under GATT. Rather, a BCA applied to exports may raise concerns under WTO subsidy rules, as described in the next point.

2. Any form of support specifically afforded to products destined for export also increases the risk of a violation of multilateral disciplines under the Agreement on Subsidies and Countervailing Measures (SCM Agreement). Under that treaty, a subsidy is defined as a financial contribution by a government that confers a benefit. This broad definition includes forgone government revenue that would otherwise be due, as is the case when a government allocates allowances for free where auctioning has otherwise become the default, when it compensates relevant costs, or when it altogether exempts exporters from compliance. Such relief will further be considered a prohibited subsidy if its award is made contingent on export performance, that is, if there is a relationship of conditionality or dependence between the award and exportation. Because an export BCA would be conditional on exportation, it could be, prima facie, classified as a prohibited subsidy (Holzer, 2014).

Combining free allocation with an import-only BCA may thus face legal challenges under multilateral free trade disciplines, but such legal risks can be lowered if certain conditions are met. While continuing the practice of free allocation for exports only raises the legal risks identified in the previous paragraph, there are ways to combine an import-only BCA with free allocation - as suggested by our ABC competitiveness analysis - so as to limit these risks. 
First, an environmental argument can be made for retaining free allocation: ensuring the competitiveness of EU producers in international markets will help safeguard their market share against foreign products that may have a higher carbon intensity. The strength of this argument will vary across industries depending on the extent of competition and on the carbon intensity of EU producers relative to the average nonEU competitor (as, in practice, an import BCA is likely to be based on default values for carbon intensity that are applied uniformly to non-EU imports, see Mehling \& Ritz 2020). What is more, if the EU retains the current benchmark-based approach, free allocation would not simply exempt exported products from the EU's carbon price, but - akin to the current system of free allocation - would continue to provide a dynamic incentive for carbon-intensity reductions through the use of best-practice benchmarks.

Second, the SCM Agreement also specifies that exemption or remission of indirect taxes for exports is admissible if it does not exceed those levied on like products sold for domestic consumption. Two conditions have to thus be met in order for this provision to sanction free allocation for exports: the application of the EU ETS to producers of goods destined for domestic consumption has to qualify as an indirect tax; and the value of freely allocated allowances must not exceed the carbon cost borne by domestically consumed goods.

While there is support for considering an ETS an indirect tax, the literature on this question is divided (de Cendra 2006; Holzer 2014). Pending relevant case law, this first condition will remain subject to legal uncertainty. For the second condition, the regulator will have to ensure that the allowances allocated for free to exporters does not exceed the amount they would otherwise have to purchase at auction if their goods were sold into the domestic market. As long as free allocation for emissions associated with exported products continues to be based on the current benchmarking system and is combined with full auctioning for emissions associated with products sold into the domestic market, this condition is likely to be met. Overall, however, there are legal risks associated with the provision of relief to exports that merit further study, including exploration of alternative ways to secure the competitiveness of exports without raising legal concerns.

\section{Conclusion}

An import-only BCA comes with an inherent asymmetry: it levels the competitive playing field in EU markets but cannot address competitiveness impacts in non-EU markets. By contrast, free allocation can support cost competitiveness of EU producers across both EU and external markets. Therefore, a move to import-only BCAs does not necessarily make redundant the continued use of free allocation to help safeguard overall industrial competitiveness. Our analysis has made this point using the equalization of effective carbon prices as a simple proxy for 
competitiveness concerns; we believe that a similar point also applies to richer metrics of competitiveness, such as market share and profitability.

Our legal analysis suggests that combining free allocation with an import-only BCA may face challenges, but also that legal risks can be reduced if certain conditions are met. While a BCA for exports has not been categorically ruled out by the EU, it is less likely to be consistent with WTO rules and therefore less likely to be proposed than an import-only BCA. Combining free allocation for exported products with a BCA on imports can increase the risk of legal challenges under multilateral free trade disciplines. Still, if the design ensures that exporters retain an incentive to lower their carbon intensity and do not benefit from free allocation in excess of the carbon pricing burden faced for domestically sold products, this risk may be hedged. Overall, further research into the legal questions raised by a BCA for exports is warranted.

Driving industrial decarbonisation while maintaining international competitiveness under the European Green Deal remains a major challenge for policymakers. A complete picture of industrial competitiveness includes a short-term level playing field and avoiding longer-term competitiveness impacts on returns to capital and new investment. BCAs may prove an important new tool to address the risk of carbon leakage. Over the longer term, meeting the objective of a competitive, decarbonised industrial sector under the European Green Deal suggests a greater role for innovation policy and research: while a rising carbon price enhances abatement incentives, it is insufficient to overcome non-price barriers to innovation and technology adoption. The capital-intensive and integrated nature of industrial production processes means that policymakers will need to strengthen support for research, development and deployment of prospective low-carbon technologies.

\section{Acknowledgements}

We thank the audience of the Cambridge EPRG 2020 Spring Seminar for a useful discussion, and three referees and the Editor for their detailed feedback.

\section{Disclosure statement}

The views expressed in this article are those of the authors and do not necessarily represent those of any organization. Since the initial submission of the paper, Michael Mehling and Robert Ritz have become engaged as advisors to the European Commission on the design and impact of border carbon adjustments. No potential conflict of interest was reported by the authors.

\section{Funding}

This paper did not receive any dedicated funding or grant award. 


\section{References}

Böhringer, Christoph, Edward J. Balistreri and Thomas F. Rutherford (2012). The role of border carbon adjustment in unilateral climate policy: Overview of an Energy Modeling Forum study (EMF 29). Energy Economics 34, S97-S110.

Branger, Frederic, Philippe Quirion, and Julien Chevallier (2016). Carbon leakage and competitiveness of cement and steel industries under the EU ETS: Much ado about nothing. The Energy Journal 37(3), 109-135.

Cosbey, Aaron, Susanne Droege, Carolyn Fischer, and Clayton Munnings (2019). Developing Guidance for Implementing Border Carbon Adjustments: Lessons, Cautions, and Research Needs from the Literature. Review of Environmental Economics and Policy 13(1), 3-22.

De Cendra, Javier (2006). Can Emissions Trading Schemes be coupled with Border Tax Adjustments? An Analysis vis-à-vis WTO Law. Review of European Community and International Environmental Law 15(2), 131-145.

Dechezleprêtre, Antoine and Misato Sato (2017). The Impacts of Environmental Regulations on Competitiveness. Review of Environmental Economics and Policy 11(2), 183-206.

Denis-Ryan Amandine, Chris Bataille and Frank Jotzo (2016). Managing carbonintensive materials in a decarbonizing world without a global price on carbon, Climate Policy 16(1), S110-S128.

Dermailly, Damien and Philippe Quirion (2006). $\mathrm{CO}_{2}$ abatement, competitiveness and leakage in the European cement industry under the EU ETS: grandfathering versus output-based allocation. Climate Policy 6, 93-113.

European Commission (2019). Communication from the Commission to the European Parliament, the European Council, the Council, the European Economic and Social Committee and the Committee of the Regions. The European Green Deal. Brussels, 11.12.2019 COM(2019) 640 final.

European Commission (2020). Inception Impact Assessment: Carbon Border Adjustment Mechanism. Ref. Ares(2020)1350037, 4 March 2020.

Fischer, Carolyn and Alan Fox (2012). Comparing policies to combat emissions leakage: Border carbon adjustments versus rebates. Journal of Environmental Economics and Management 64, 199-216.

Hecht, Melania and Wolfgang Peters (2019). Border adjustments supplementing nationally determined carbon pricing. Environmental and Resource Economics 73, 93109. 
Helm, Dieter, Cameron Hepburn and Giovanni Ruta (2012). Trade, climate change, and the political game theory of border carbon adjustments. Oxford Review of Economic Policy 28(2), 368-394.

Hillman, Jennifer (2013). Changing Climate for Carbon Taxes: Who's Afraid of the WTO? German Marshall Fund of the United States Climate and Energy Paper Series. Washington, DC.

Holzer, Kateryna (2014). Carbon-Related Border Adjustment and WTO Law. Cheltenham, Edward Elgar.

I4CE (2015). Exploring the EU ETS beyond 2020: A first assessment of the EU Commission's proposals for Phase IV of the EU ETS (2021-2030). COPEC Research Program: The Coordination of EU policies on Energy and CO2 with the EU ETS by 2030. Institute for Climate Economics and Enerdata, November 2015.

IPCC (2018). Summary for Policymakers. In: Global Warming of $1.5^{\circ} \mathrm{C}$. An IPCC Special Report on the impacts of global warming of $1.5^{\circ} \mathrm{C}$ above pre-industrial levels and related global greenhouse gas emission pathways, in the context of strengthening the global response to the threat of climate change, sustainable development, and efforts to eradicate poverty [Masson-Delmotte, V., P. Zhai, H.-O. Pörtner, D. Roberts, J. Skea, P.R. Shukla, A. Pirani, W. Moufouma-Okia, C. Péan, R. Pidcock, S. Connors, J.B.R. Matthews, Y. Chen, X. Zhou, M.I. Gomis, E. Lonnoy, T. Maycock, M. Tignor, and T. Waterfield (eds.)]. World Meteorological Organization, Geneva, Switzerland, 32 pp.

Ismer, Roland and Karsten Neuhoff. (2004). Border Tax Adjustments: A Feasible Way to Address Non-Participation in Emission Trading. CMI Working Paper 36, Faculty of Economics, University of Cambridge.

Joltreau Eugenie and Katrin Sommerfeld (2019). Why does emissions trading under the EU Emissions Trading System (ETS) not affect firms' competitiveness? Empirical findings from the literature. Climate Policy 19(4), 453-471.

Marcu, Andrei, Michael Mehling, and Aaron Cosbey (2020) Border Carbon Adjustments in the EU: Issues and Options. European Roundtable on Climate Change and Sustainable Transition, Brussels.

Martin, Ralf, Mirabelle Muûls, and Ulrich J. Wagner (2016). The Impact of the European Union Emissions Trading Scheme on Regulated Firms: What Is the Evidence after Ten Years? Review of Environmental Economics and Policy 10(1), 129-148. Mehling, Michael, Harro van Asselt, Kasturi Das, Susanne Dröge, and Cleo Verkuijl (2019). Designing Border Carbon Adjustments for Enhanced Climate Action. American Journal of International Law 113(3), 433-481. 
Mehling, Michael A. and Robert A. Ritz (2020). Going Beyond Default Intensities in an EU Carbon Border Adjustment Mechanism. Cambridge Working Papers in Economics 2087, Faculty of Economics, University of Cambridge.

Naegele Helene and Aleksandar Zaklan (2019). Does the EU ETS cause carbon leakage in European manufacturing? Journal of Environmental Economics and Management 93, 125-147.

Neuhoff, Karsten, Roland Ismer, et al. (2016). Inclusion of consumption of carbonintensive materials in emissions trading: An option for carbon pricing post-2020. Report by Climate Strategies, May 2016.

Neuhoff, Karsten and Robert A. Ritz (2019). Carbon cost pass-through in industrial sectors. EPRG Working Paper 1935, Faculty of Economics, University of Cambridge. Hector Pollitt, Karsten Neuhoff and Xinru Lin (2020). The impact of implementing a consumption charge on carbon-intensive materials in Europe, Climate Policy, 20:sup1, S74-S89.

Porter, Michael E. (1991). America's green strategy. Scientific American 264(4), 168

Porter, Michael E. and Claas van der Linde (1995). Toward a new conception of the environment-competitiveness relationship. Journal of Economic Perspectives 9(4), 97118.

Reinaud, Julia (2005). Industrial competitiveness under the European Union Emissions Trading Scheme. International Energy Agency, Information Paper, February 2005.

Venmans, Frank, Jane Ellis, and Daniel Nachtigall (2020). Carbon pricing and competitiveness: Are they at odds? Climate Policy 20(9), 1070-1091.

Verde, Stefano, Teixidó, Jordi, Marcantonini, Claudio \& Labandeira, Xavier (2019). Free allocation rules in the EU emissions trading system: what does the empirical literature show?, Climate Policy 19(4), 439-452.

World Bank (2020). State and Trends of Carbon Pricing 2020. Washington DC, May 2020.

World Trade Organization and United Nations Environment Programme (2009). Trade and Climate Change. Geneva: WTO et al.

\footnotetext{
${ }^{1}$ Vivid Economics

${ }^{2}$ Grantham Research Institute on Climate Change and the Environment, London School of Economics

${ }^{3}$ Center for Energy and Environmental Policy Research (CEEPR), Massachusetts Institute of Technology

${ }^{4}$ Energy Policy Research Group (EPRG), Judge Business School, Cambridge University
} 


\footnotetext{
${ }^{5}$ Edelman Advisory

* Corresponding author: Dr Robert Ritz (r.ritz@jbs.cam.ac.uk)
}

${ }^{6}$ See Neuhoff, Ismer et al. (2016) argue that an alternative policy based on instead levying a carbon price on the domestic consumption of carbon-intensive materials (rather than the current production-based approach of the EU ETS) is superior to current policy on free allocation as well as border carbon adjustments.

${ }^{7}$ France had previously already proposed to introduce a BCA as part of a "fair ecological transition". Outside Europe, BCAs have precedent at a sub-national level in California's carbon trading system.

${ }^{8}$ The EU is considering several design options, including a carbon tax on selected products (both on imports and domestic production), a new carbon customs duty or tax on imports, or the extension of the EU ETS to imports. ${ }^{9}$ An export BCA incurs a two-fold risk of violating international trade law, as it may not benefit from the exemption of Article XX of the General Agreement on Tariffs and Trade which allows measures necessary to protect the environment or related to the conservation of exhaustible resources, and as it would be conditional on exportation, it could be, prima facie, classified as a prohibited subsidy under the Agreement on Subsidies and Countervailing Measures, see Holzer (2014).

${ }^{10}$ Most industries are likely to be able pass-through carbon costs to some extent creating a risk that free allocations leads to windfall gains; however, the tightening of rules in Phase IV of the EU ETS is likely to better target free allocations to those sectors where the capacity for cost pass-through is limited (Verde, Teixidó, Marcantonini \& Labandeira, 2019).

${ }^{11}$ Neuhoff \& Ritz (2019) synthesize the theory and evidence on the pass-through of carbon costs to product prices by industrial sectors in light of their market structure, international trade exposure, and the design of free allocation.

${ }^{12}$ See Denis-Ryan, Bataille \& Jotzo (2016) for a wider analysis of the challenges to deep decarbonization of carbon-intensive materials by national climate policy in the absence of a global carbon price.

${ }^{13}$ Hecht \& Peters (2019) model a three-stage game involving carbon price competition in the first stage, the introduction of BAs in the second stage and oligopolistic competition between firms in the third stage

${ }^{14}$ The "Porter Hypothesis" (Porter 1991; Porter \& van der Linde 1995) holds that environmental regulation such as carbon pricing can be beneficial for long-run competitiveness by stimulating innovation and investment. See I4CE (2015) for a recent analysis in the context of the EU ETS. In terms of our ABC framework, this adds another dimension to our long-run competitiveness Channel $\mathrm{C}$ - but does not alter the arguments we make about short-term cost competitiveness along Channels A and B.

15 The same is true for grandfathering that uses sector-performance standards, which seeks to facilitate movement to lower emissions forms of production but is still effectively a lump-sum transfer.

${ }^{16}$ The EU ETS's New Entrants Reserve also supports new entrants by providing benchmarked free allocations to new installations joining the EU ETS or for installations whose capacity has significantly increased since their free allocation was determined.

${ }^{17}$ By diluting the carbon price, and hence near-term abatement incentives, free allocation may lead to "carbon lock-in" in industrial sectors that, over time, can increase the required volume of low-carbon investment-and thereby undermine longer-term industrial competitiveness.

${ }^{18}$ This aligns with the likely focus of the EU's proposed BCA: "Carbon leakage occurs when production is transferred from the EU to other countries with lower ambition for emission reduction, or when EU products are replaced by more carbon-intensive imports... a carbon border adjustment mechanism would ensure that the price of imports reflect more accurately their carbon content." See EU Inception Impact Analysis, 2020, available at https://ec.europa.eu/info/law/better-regulation/have-your-say/initiatives/12228-Carbon-Border-AdjustmentMechanism

${ }^{19}$ Eurofer (2018) http://www.eurofer.org/News\%26Events/PublicationsLinksList/201806-SteelFigures.pdf. 